\title{
- Characterization of Gem and Abrasive Variety Corundum from Wyra Area of Khammam Schist Belt, Telangana, India, Using Advanced Spectroscopic Techniques
}

\section{S. U. Shyam Kumar, N. Shadakshara Swamy}

Department of Geology, Bangalore University, Bangalore, India-560056.

\section{ABSTRACT}

Corundum of varying qualities occurring in association with Khammam schist belt are studied with respect to their Geochemical and Mineralogical aspects. Studies have been carried out using the advanced spectroscopic techniques namely, Photoluminescence, UV-Visible, FT-IR, Raman and EDXRF analysis. The results obtained from the studies shows the predominance of colour causing element $\mathrm{Cr}$ and other associated elements like, $\mathrm{Ti}, \mathrm{V}$ and $\mathrm{Ga}$ in Red variety of corundum than the abrasive corundum crystals, while $\mathrm{Fe}$ is found predominant in colourless or abrasive variety. From EDXRF studies the presence of impurity ions in the crystal lattice is quantified and its effect on the corundum crystal has been ascertained.

Key Words: Corundum, Ruby, Telangana, Spectroscopy, Cause of colour

\section{INTRODUCTION AND GEOLOGY}

In and around Wyra taluk in the Khammam district of Telangana, India, occurrences of corundum of abrasive variety and rarely of gem variety are observed. The study area lies in the Khammam schist belt (KSB) which is a continuation and part of the Nellore-Khammam Schist belt (NKSB) (Ramam and Murthy, 1997).

The main lithology of the area include amphibolite, schists and gneisses of varying compositions, anorthosites, pegmatites and quartz veins, corundum bearing magnesium and aluminum rich pelitic granulites and hornblende pyroxene granulites (Ramam and Murthy, 1997; Patil, 1973). Metamorphosed pelitic, psammitic and calcareous sediments are represented by garnetiferous biotitemuscovite-kyanite-chlorite schists, kyanite and sillimanite bearing meta - pelitic schists, calc -silicate rocks, quartzites, fuchsite, and magnetite quartzite. The meta-sedimentary unit is tectonically emplaced below a metavolcanic unit made up of quartz-chlorite schists, hornblende schists and

\section{Corresponding Author:}

S. U. Shyam Kumar, Department of Geology, Bangalore University, Bangalore, India-560056.

Email: shyamkumarsu@gmail.com

ISSN: 2231-2196 (Print)

ISSN: 0975-5241 (Online)

DOI: 10.7324/IJCRR.2017.9163

Received: 28.07.2017 tonalitic gneisses (Ramam and Murthy,1997; Leelanandam and Narasimha,1988; Narayan and Pavanaguru, 2013).

The main host rocks for corundum in the study area are sillimanite-corundum schist and kyanite schists. These pelitic schists hosting corundum are found to be in contact with altered basic bodies or pegmatitic vein. Occurrences associated with pyroxene granulites and gneisses are also seen in some localities of the Wyra taluk. Similar Geological setups hosting corundum have been reported from the study area (Patil, 1973; Rao,1981; Narayan and Pavanaguru,2013). However, corundum crystals for the present study are obtained from placer concentrations seen to occur locally in the soil profile.

Samples of gem variety as well as abrasive variety of corundum are collected from these areas and, 2 samples of contrasting qualities are selected for studies.

\section{MATERIALS AND METHODS}

Samples collected from the study area are analyzed based on its visual appearance and it has been grouped on that 
basis. Two Corundum samples are sorted from them based on the colour and gemological quality so that, one sample is of abrasive quality with colourless nature ( C1, Fig.1) where as the other one is of semi precious variety with pinkish red colour (C2, Fig.2).

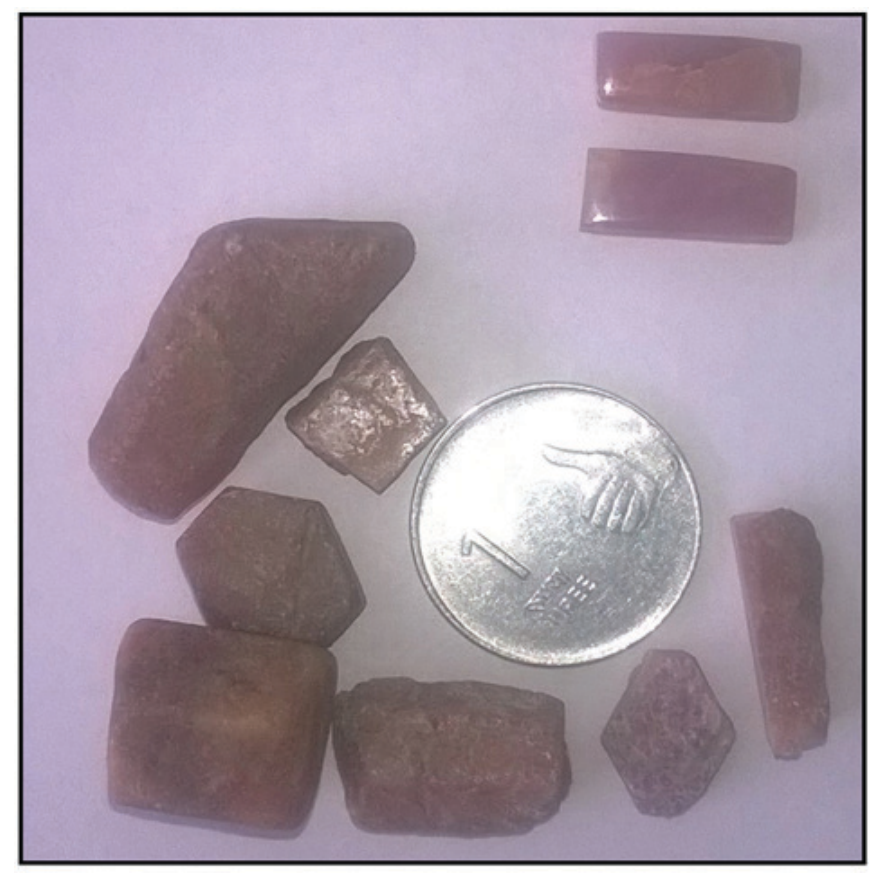

Figure 1: Showing C1 sample - Natural as well as in polished form.

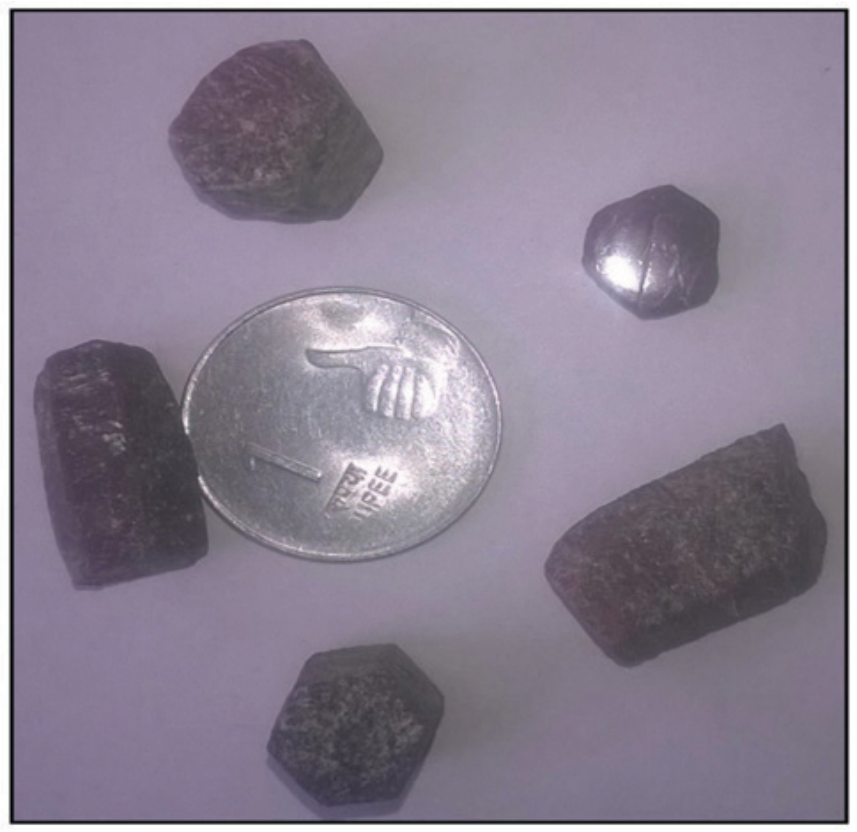

Figure 2: Showing C2 sample - Natural as well as in polished form.

Both the samples $\mathrm{C} 1$ and $\mathrm{C} 2$ after preliminary cleaning and acid treatment were cut into suitable size and then subjected to the following analyses namely, UV-Visible Spectroscopy,
Photoluminescence spectroscopy, FT-IR Spectroscopy, Raman Spectroscopy and EDXRF studies.

\section{RESULTS AND DISCUSSIONS}

The spectra obtained for both the gem and abrasive variety samples using different advanced spectroscopic analyses are displayed with contrasting colours. The UV-Visible spectra obtained for the samples in the wavelength range of $200 \mathrm{~nm}$ to $600 \mathrm{~nm}$ and Photoluminescence peaks in the wavelength range of $600 \mathrm{~nm}$ to $800 \mathrm{~nm}$ are shown in Figure. 3 and Figure.4 respectively. Vibrational Spectroscopic studies on the samples using the Fourier Transform Infrared (FTIR) Spectroscopy and the Raman Spectroscopy are discussed separately. Figure 5 and Figure 6 depicts the spectra obtained using FTIR Spectroscopy in a wavelength range between $4000 \mathrm{~cm}^{-1}$ to $500 \mathrm{~cm}^{-1}$ and Raman Spectroscopy in Raman shifts ranging from $200 \mathrm{~cm}^{-1}$ to $800 \mathrm{~cm}^{-1}$, respectively. Results obtained from EDXRF Studies are discussed and correlated with the observations made from other Spectroscopic techniques used in the research.

\section{UV-Visible and Photoluminescence Spectroscopy}

The UV-Visible spectra of the two samples are observed in the wavelength range of 200 to $600 \mathrm{~nm}$ (Figure.3). The spectra show significant difference in the peaks obtained at certain wavelengths. The peaks shown by the $\mathrm{C} 2$ sample are of more intensity and magnitude compared to that of C1 sample, indicating the presence of certain additional elements in $\mathrm{C} 2$, which has favored in imparting pinkish red colour. Peaks in the range of 200 to $250 \mathrm{~nm}$ are more densely spaced in the $\mathrm{C} 1$ variety of corundum sample. A prominent peak at $241 \mathrm{~nm}$ is seen in C1. The hydroxylated ions present in samples correspond to absorptions in this wavelength. Such ions are hence present in higher concentration in the $\mathrm{C} 1$ variety.

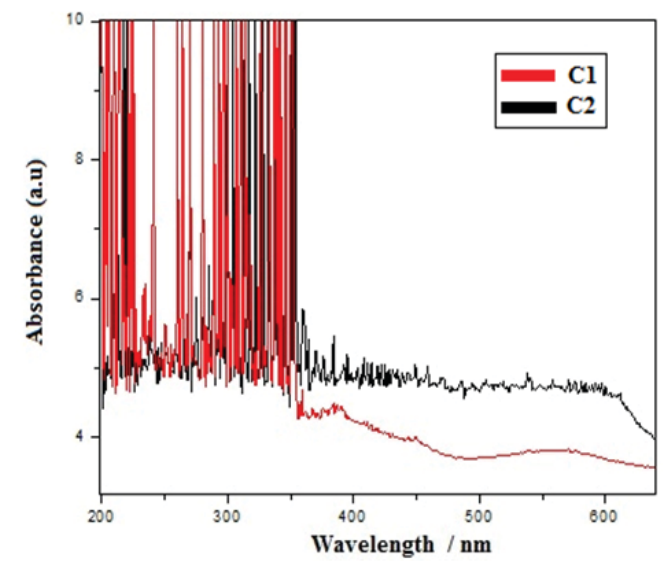

Figure 3: The UV-Vis spectra of both the samples are shown, where $\mathrm{C} 1$ is represented by red peaks and $\mathrm{C} 2$ by black colour. 
Correlation of the absorbance peaks clearly shows a contrast in the peaks at wavelengths corresponding to $\mathrm{Fe}$ and $\mathrm{Cr}$, the usual colour causing ions in ruby variety of corundum. Some of the studies (Nassau et al.,1983; Jatin and Pratima, 2015) has shown that, the wavelengths that are usually absorbed by Fe ions falls under the range of 380 to $400 \mathrm{~nm}$ whereas, peaks are observed to be present at 401, 461, 467, 475 and $535 \mathrm{~nm}$ when the $\mathrm{Cr}$ ions shows its prominence. In the absorbance spectra of the samples, $\mathrm{C} 1$ is having peaks of very minute magnitude in the wavelength range corresponding to $\mathrm{Fe}$ ions and it doesn't shows any absorbance in the range of $\mathrm{Cr}$ ions. It is identified that, the peaks in this range, corresponding to $\mathrm{Fe}$ and $\mathrm{Cr}$ are present in $\mathrm{C} 2$ with a comparatively appreciable magnitude, which justifies the cause of colour in the $\mathrm{C} 2$ sample compared to $\mathrm{C} 1$.

The Luminescence peaks are observed for both of the samples in an excited state at $401 \mathrm{~nm}$ (Figure 4). Luminescence peaks lies in the wavelength range between 600 to $800 \mathrm{~nm}$. The dual peak at 692 and 694 represents the presence of $\mathrm{Cr}$ chromophores in both the samples (Nassau et al.,1983; Beran and Rossman et al., 2006; Jatin and Pratima, 2015).

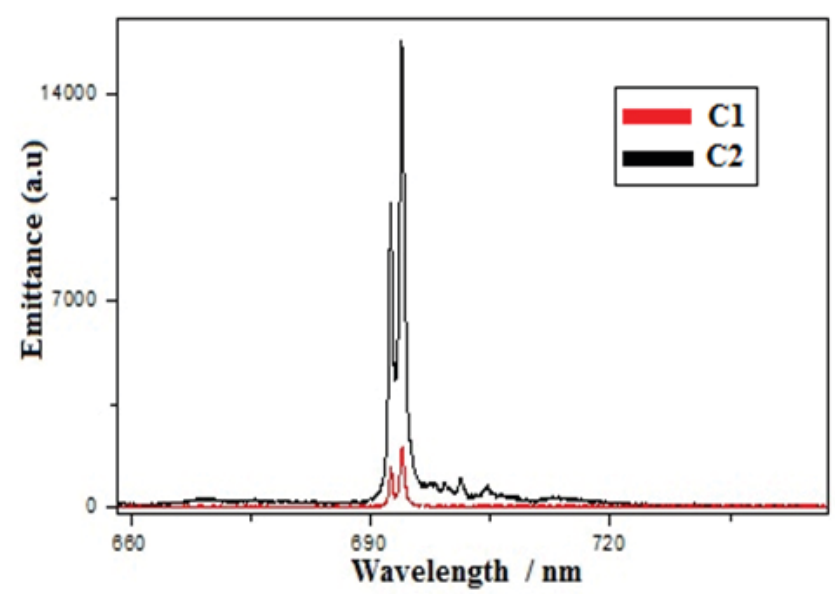

Figure 4: The luminescence spectra of both the samples are shown, where $\mathrm{C} 1$ is represented by red peaks and $\mathrm{C} 2$ by black colour.

Even though $\mathrm{C} 1$ sample has a significant peak at the above mentioned wavelengths, the magnitude is much lesser than that of $\mathrm{C} 2$. The very high magnitude of the peaks obtained for $\mathrm{C} 2$ samples substantiates its cause of colour due to prominent presence of $\mathrm{Cr}$.

\section{FT-IR Spectroscopy}

Fourier Transform Infrared Spectroscopy or FT-IR Spectroscopy data of the samples is observed (Figure 5) in a wavelength range between $4000 \mathrm{~cm}^{-1}$ to $500 \mathrm{~cm}^{-1}$. The spectra seen between 500 to $1000 \mathrm{~cm}^{-1}$ is of the same fashion with peaks at common wavelengths. Both the samples show peaks corresponding to same wavelengths, even though the $\mathrm{C} 1$ sample has a comparatively lesser magnitude. Therefore, these peaks are generally identified to be caused by the Alumina present in the crystal.

There are no considerable peaks seen in the $\mathrm{C} 1$ sample after $1000 \mathrm{~cm}^{-1}$. Twin peaks observed in $\mathrm{C} 2$ sample at 1991 and $2100 \mathrm{~cm}^{-1}$. Similar peaks are observed (Cowley, 1969; Kloprogge et al., 2004; Jatin and Pratima, 2015), indicating the presence of hydroxylated form of Alumina, corresponding to high temperature environment and the peaks seen in the wavelength range towards higher energy part is all corresponding to different hydroxylated ions in the crystal lattice. These are caused by the vibration modes related with the bending and stretching of $-\mathrm{OH}$ group bonds in the crystal lattice and the mineral groups that may be present cannot be always presumed to be due to the $\mathrm{OH}$ association with Alumina groups. Such hydroxylated groups are similarly observed (Beran and Rossman, 2006; Kloprogge et al., 2004) to be due to the presence of other elements like $\mathrm{Ti}, \mathrm{Fe}$ or $\mathrm{V}$ present in the crystal lattice in traces.

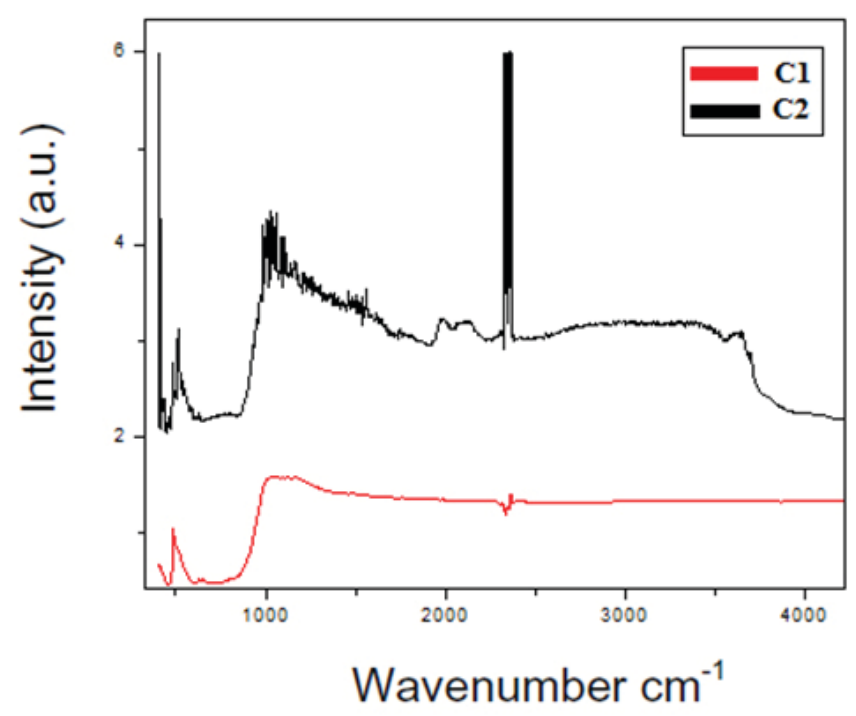

Figure 5: The FTIR spectra of both the samples are shown, where $\mathrm{C} 1$ is represented by red peaks and $\mathrm{C} 2$ by black colour.

\section{Raman Spectroscopy}

Raman spectroscopy is depended on the vibrational modes of the substances subjected to analysis. Corundum is reported to have 18 vibrational modes where 7 are Raman active, 6 are Infrared active while the rest are neither Raman nor Infrared active and unique vibrations for Corundum are usually observed at 378, 418, 432, 451, 578, 645 and $751 \mathrm{~cm}^{-1}$ (Porto and Krishnan, 1967; XU J-A et al., 1995; Jasinevicius, 2009). Individual spectra of both the samples $\mathrm{C} 1$ and $\mathrm{C} 2$ are well observed (Figure 6). The spectra obtained for $\mathrm{C} 1$ sample is devoid of any considerable peaks and is almost following a plain linear fashion. 


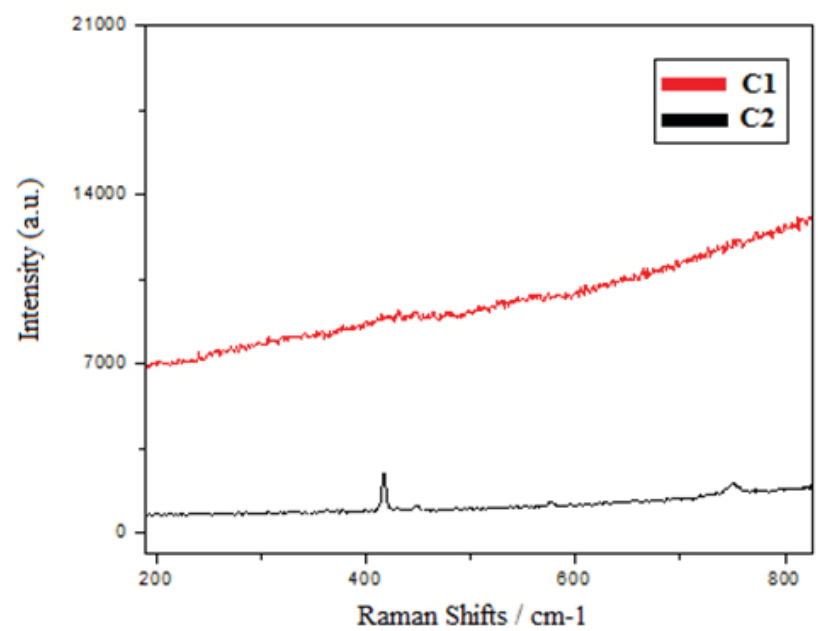

Figure 6: The Raman spectra of both the samples are shown, where $\mathrm{C} 1$ is represented by red colour and $\mathrm{C} 2$ by black.

In contrary, the spectra of $\mathrm{C} 2$ sample is showing a notable peak at $417 \mathrm{~cm}^{-1}$, a minute peak at $750 \mathrm{~cm}^{-1}$ and a very minute one at $577 \mathrm{~cm}^{-1}$. These peaks correspond to the typical fundamental vibrations evidenced in corundum, which are also believed to be associated with Alumina.

\section{Geochemical Analysis}

Characterization of the two variety of corundum in terms of chemical composition is highly essential in determining the cause of colour and other allied properties in Gemological perspective. The average weight percentage in terms of oxides of $\mathrm{Al}, \mathrm{Ca}, \mathrm{Ti}, \mathrm{V}, \mathrm{Cr}, \mathrm{Fe}, \mathrm{Ga}$ and $\mathrm{Zr}$ are obtained from the Energy Dispersive X Ray Fluorescence (EDXRF) Spectroscopy.

The presence of other oxides in the $\mathrm{C} 1$ samples is estimated to be within 0.8 weight percentage and the crystal is mere corundum with higher content of $\mathrm{Al}_{2} \mathrm{O}_{3}$ alone, even though 0.3 weight percentage of $\mathrm{Fe}_{2} \mathrm{O}_{3}$ is also observed. The $\mathrm{C} 2$ sample shows 95.3 weight percentage of $\mathrm{Al}_{2} \mathrm{O}_{3}$ while other oxides constitutes for an average weight percentage of 3.179 out of which, $\mathrm{Cr}_{2} \mathrm{O}_{3}$ predominates with 1.882 by weight percentage followed by, $\mathrm{TiO}_{2}, \mathrm{CaO}$ and $\mathrm{ZrO}_{2}$.

\section{CONCLUSIONS}

Present study indicates subtle differences in the two samples. The UV-Visible spectra shows continuous peaks in the wavelength range from 401 to 535 in the $\mathrm{C} 2$ sample, while it remains absent in that of $\mathrm{C} 1$, revealing the predominance of $\mathrm{Cr}$ ions in $\mathrm{C} 2$ sample. The emission spectra due to Photoluminescence, has prominent dual peaks in the wavelengths 692 and $694 \mathrm{~nm}$ in C2 sample while these peaks are present in a very less magnitude in the $\mathrm{C} 1$ sample. This accounts to the prominence of $\mathrm{Cr}$ chromospheres in C2 sample. Peaks obtained from the FTIR spectra, in the higher energy level prior to $1000 \mathrm{~cm}^{-1}$, throws light on the existence of several hydroxylated ions in the crystal, along with Alumina in the $\mathrm{C} 2$ sample while, peaks in this range remains absent in $\mathrm{C} 1$. The Raman spectra shows peaks at the typical fundamental vibrational modes corresponding to their respective Raman Shifts $\mathrm{cm}^{-1}$ at 417, 750 and 577, in the C2 sample, while $\mathrm{C} 1$ sample is showing a spectra devoid of such peaks. EDXRF data substantiated the results obtained from other advanced spectroscopic analyses as it confirms that the presence of $\mathrm{Cr}_{2} \mathrm{O}_{3}$ and $\mathrm{TiO}_{2}$, which are desirable constituents of quality rubies is predominant in $\mathrm{C} 2$ sample, while, the quantity of $\mathrm{Fe}_{2} \mathrm{O}_{3}$ is higher in $\mathrm{C} 1$. This study has been proven helpful in characterizing and determining the parameters and features present in the two varieties of samples collected from the study area, that are responsible for causing colour in them.

\section{ACKNOWLEDGEMENT}

The authors are thankful to the Chairperson, Department of Geology, Bangalore University, Bangalore, for providing research facilities. We are grateful to Dr. M.D. Sastry, Head, R\&D and Shri.K.T. Ramachandran, Chief Gemologist \& Executive Secretary, of the Gemological Institute of India, Mumbai, for extending facilities for carrying the advanced spectroscopic analyses at their R\&D Laboratory.

\section{REFERENCES}

1. Beran, A and Rossman, G.R (2006) OH in naturally occurring corundum. European. Jour. Mineralogy., Vol.18, PP.441-447.

2. Bhagavantam, S and Venkatarayudu, T (1939) Raman effect in relation to Crystal Structure. Proc. Indan. Acad. Sci,, Vol.9, PP.224-58.

3. Cowley, E.R (1969) Symmetry properties of normal modes of Vibration of Calcite and Corundum. Can. Jou. Phys., Vol.47, PP.1381-1391.

4. Jasinevicius, R (2009) Characterization of vibrational and electronic features in the Raman spectra of gem minerals. MSc Thesis, Grad. College, University of Arizona., 147P.

5. Jatin Kumar Sinha and Pratima Kumari Mishra (2015) Spectroscopic and Microstructural Studies of Ruby Gemstones of Sinapalli, Odisha. Jour. Geol. Soc. India., Vol. 86, PP.657-662.

6. Kloprogge, J.T., Hickey, L and Frost, R.L (2004) FT-Raman and FT-IR spectroscopic study of synthetic $\mathrm{Mg} / \mathrm{Zn}$ /Alhydrotalcites. Jour. Raman. Spectroscopy., Vol.35, PP.967-974.

7. Leelanandam, C and Narsimha Reddy, M (1988) Precambrian anorthosites from Peninsular India- Problems \& Perspectives. Indian. Jour. Geol, Vol.60, PP.111-136.

8. Narayan Sangam and Pavanaguru, R (2013) Geology of Corundum Occurrances in Parts of Khammam Schist Belt. IJSRP., Vol.3, 3P.

9. Nassau, K (2001) The Physics and Chemistry of Color: The fifteen causes of color (Second Edition), Wiley, New York, 454P.

10. Patil R. D (1973) Report On The Investigation For Corundum Near Gobbagurti, Khammam District, Andhra Pradesh. Geol. Surv. India, unpublished report. PP.1-4. 
11. Porto, S.P.S and Krishnan, R.S (1967) Raman Effect of Corundum. Jour. Chemical. Physics, Vol.47, PP.1009-1012.

12. Ramam, P. K and Murthy, V. N (1997) Geology of Andhra Pradesh. Jour. Geol. Soc. India. Bangalore., 245P.

13. Rao, N. A (1981) Report On The Investigation For Corundum In Khammam District, Andhra Pradesh. Geol. Surv. India., unpublished report. PP.1-4.

14. Richet, P., Gillet, P., Pierre, A., Bouhifd, M.A., Daniel, I and Fiquet, G (1993) Raman spectroscopy, x-ray diffraction, and phase relationship determinations with a versatile heating cell for measurements up to $3600 \mathrm{~K}$ (or $2700 \mathrm{~K}$ in air). Jour. Appld. Phys., Vol.74, PP.5451-5456.

15. Xu J-A, Huang E, Lin J-F, Xu LY (1995) Raman study at high pressure and the thermodynamic properties of corundum: Application of Kieffer's model. Ameican Mineralogist., Vol.80, PP.1157-1165. 